\title{
Benefits of the empathy map method and the satisfaction of a company with its application in the development of concepts for a white glue tube
}

\author{
Carina Campese, Camila Alejandra Leon Vanegas, Janaina Mascarenhas Hornos da Costa \\ Universidade de São Paulo - USP \\ e-mails: carinacampese@yahoo.de; camila.a.leon.v@gmail.com; janainamhcosta@gmail.com
}

\begin{abstract}
User-centered design (UCD) can be understood as a philosophy, a process, or even an approach, that has the objective to increase the consideration of user needs in the design process. In particular, an empathy map is a UCD method that seeks the definition of a user profile and user needs. Because the method is gaining importance in the literature and in applications to perform services and design products, we report on an application of the empathy map method and evaluate its usefulness. The empathy map was applied by 25 trainees in a controlled experiment in the concept phase for a white glue tube design process, in a partnership with a company that produces office supplies. The method helped in many aspects, mainly in organizing the information collected and understanding the user. Both the students and the company were satisfied with the results that the method provided.
\end{abstract}

Keywords: user centred design, empathy map, UCD methods, persona, user involvement.

\section{Introduction}

User-centered design is a design philosophy that adds deep consideration of human needs to the design process, whatever the product or service, whatever the major focus. It should start with a good understanding of users and their needs that the design is intended to meet (NORMAN, 2013).

There are diverse methods and techniques that can assist designers to see through the user's eye allowing them to understand the user and their needs. Personas (MAGUIRE, 2001; RIPPON, 2006), empathy map (BRATSBERG, 2012; MÜLLER, 2010), cognitive walkthough (ABRAS; MALONEY-KRICHMAR; PREECE, 2004; VAN KUIJK; VAN DRIEL; VAN EIJK, 2015), user stories (BERTHOLDO et al., 2014; SILVA et al., 2011), scenarios (JURCA; HELLMANN; MAURER, 2014; SILVA et al., 2011) and heuristic evaluation (MAO; VREDENBURG, 2000; RIPPON, 2006) are some examples of UCD methods. Although the extensive amount of citations regarding the applicability and intended benefits of these methods, there is still a lack of reports of its actual application, which can help companies use these methods properly.

Identifying user requirements (by analyzing their needs and issues) at the beginning of product development is of the utmost importance (PRESSMAN, 2010), but it is necessary to do this analysis using proven methods, not by means of flatworms. Some methods with the purpose of identifying user requirements are already well studied in the literature (e.g., persona (HJALMARSSON, 2015; MAGUIRE, 2001; RIPPON, 2006)), but the empathy map has been getting more attention lately (VIANNA et al., 2012).

The empathy map promises to synthesize information about the users and to identify their needs (PLATTNER, 2010) and their different points of view (CHEN; CHOU, 2013) about a particular product or service. The demand for this method is clear, but the difficulties of applying and subsequently using this information integrated into a product development process are relevant. These difficulties can be confirmed by the low number of studies that focus on the application of the empathy map to serve as a reference for companies.

The aim of this paper is to evaluate the usefulness of the empathy map method. Furthermore it is reported an application of the empathy map and discussed the difficulties of application, effort, and utility in the concept phase of design process and satisfaction of the results that the method provides are analyzed.

This application took place through a partnership of a multinational company that produces office supplies with the University of Sao Paulo. The company developed a project to develop concepts of white glue tube with undergraduate students attending the Manufacturing and Material Engineering course. The students presented different concepts of new white glue tube, and the company 
chose the best one. This concept was later developed by the company and launched in the Brazilian market.

The results obtained show that the empathy map method was very significant during the project, assisting the students as project team to understand the user and their needs, to keep the continuously focus on the user, to make decisions and to generate a good concept that could satisfy all the needs identified before.

\section{Literature review}

\subsection{Empathy map}

According to Plattner (2010), empathy is the foundation of a human-centered design process because you need to understand the people for whom you are designing. Watching what people do and how they interact with the environment gives clues about what they think and feel, and some physical manifestations give insights about what they do and say. Although the best solutions come out of the best insights into human behavior, learning to recognize those insights is not easy. It is necessary to see things with a fresh set of eyes, and tools for empathy can help give those new eyes. An empathy map is a tool to help synthesize observations and draw out unexpected insights (PLATTNER, 2010).

The tool was developed by a company of visual thinking, XPLANE. It is defined as a "simple customer profiler" helping to sketch the customer profile beyond the demographic sector, including environmental and emotional aspects (OSTERWALDER; PIGNEUR, 2010). The empathy map is a tool for the synthesis of information on the client through visualization of what he or she says, does, thinks, and feels. The data provide an understanding of situations arising from the context, behavior, concerns, and aspirations of the user (VIANNA et al., 2012). Through the method's application, clear hypotheses are established regarding the needs of the users, as well as their behavior and other characteristics (OSTERWALDER; PIGNEUR, 2010), and this makes it possible for the project team to elicit the user requirements.

The empathy map is useful when you have a lot of data from the field and you need to organize it to generate a better understanding of your target audience (VIANNA et al., 2012). The data should be organized into a diagram broken down in six areas, and the center provides a characterization of the client (name, personal characteristics, etc.). Each area is filled in with information about:

- See: description of what the client sees in his/her environment.

- Hear: description of how the environment influences the client.
- Think and feel: exercise geared towards understanding how the client's mind works.

- Say and do: exercise geared towards how the client behaves in public and what he is thinking.

- Difficulties: description of the obstacles faced by the client during his experience.

- Achievements: description of positive and promising attributes of the client.

It is noteworthy that thoughts and feelings cannot be observed directly; they must be inferred by paying attention to some clues, such as body language, tone, and choice of words (PLATTNER, 2010). It is also important to identify needs, which are human or physical necessities; they help in defining the design challenge.

The goal of the method is to enter the customer's mind to find out his or her needs, desires, fears, and wishes, to reach the customer in a surefire way. The intent is to capture insights from the clients - just asking them once is usually not enough. It is necessary to adopt their perspective to find new ideas (OSTERWALDER; PIGNEUR, 2010).

Kouprie and Visser (2009) propose three key elements to achieve user empathy effectively in product design: (1) motivation (when designers do not realize the benefits of having empathy, project results may be unsatisfactory); (2) the awareness that the process of generating empathy encompasses a combination of effective and cognitive components - that is, it is necessary to enter into the user's life and reflect on it; and (3) time, since an empathy process requires an investment of time. Whether or not that time is available is often the first barrier in generating empathy.

With the application of the empathy map method, it can be obtained information that contributes to the product or service's design, such as:

- Understand the user: with the application of the method, it is possible to understand the users, understanding the world through their eyes and their perspectives. In this way, assumptions about the user are eliminated, because real data are obtained throughinterviews and observations made with the user (BRATSBERG, 2012);

- User needs: through the interpretation of the results of the method, the needs of the users interviewed are obtained, revealing opportunities for the purpose of establishing a relationship and getting to know more about what is wanted of the product or service (BRATSBERG, 2012);

- Identification of new concepts: the analysis of the results of the method allows designers to transform the observations into graphic and visual 
representations, and these into different concepts that meet the users' needs (KOUPRIE; VISSER, 2009; LEONARD; RAYPORT, 1997).

The application of the empathy map can then bring numerous benefits to the development of products.

\subsection{Persona}

One of the problems of the development process is the failure to recognize the needs of the user and to specify them in a way that the designers can incorporate in the project. Persona is a method that supports user and organizational requirements specifications in order to overcome the problem presented. Personas represent user's need to the design team through caricatures that receive name, personality and picture and represent the most important user groups (MAGUIRE, 2001).

Personas are models that allow the understanding of the user's goals in specific contexts. Although they're not real users, they represent them throughout the design process, they are hypothetical archetypes of actual users. They're defined with significant rigor and precision based on the investigation process, just their names and personal details are imaginary (COOPER et al., 2014).

Personas are an important tool to communicate about different types of users and their needs and then deciding which users are the most important to target in the design of form and behavior. In this sense is an important method because the best way to successfully accommodate a variety of users is to design for specific types of individuals with specific needs (COOPER et al., 2014).

The greatest advantages of the method are to determine what a product should do and how it should behave, communicate with stakeholders, build consensus and commitment to the design, measure the design's effectiveness and contribute to other product-related efforts. Also, they engage the empathy of the design and development team around the user's goals, and that's a critical aspect because the team will make their decisions based on the person's cognitive and emotional dimensions (COOPER et al., 2014).

Besides, this method helps the designers on keeping in mind the users' needs, helps on getting a better communication between the designers about the users, guides the design decisions and helps on requirements prioritization (HJALMARSSON, 2015; MIASKIEWICZ; KOZAR, 2011).

Although the many benefits, persona has some critics. The creation of Persona is based on the designers' ability to accurately portray the personality of the interviewed person. Because of that, any problem in generating persona information and in about the skill level of the designers, can weak the project (BAGNALL; DEWSBURY; SOMMERVILLE, 2005).
Another weak point is when the design if for a large population because a single persona could not represent the whole group and the implementation and control of several personas would be hard for the designers (BAGNALL; DEWSBURY; SOMMERVILLE, 2005; CHAPMAN; MILHAM, 2006). Another limitation of the method is that it can not be validated, in other words, there is no real data that could prove a persona (CHAPMAN; MILHAM, 2006).

\section{Methodology}

The objective of this paper is to evaluate the empathy map method. This evaluation was carried out by means of a controlled experiment (SHADISH; COOK; CAMPBELL, 2002) with the objective of (1) testing the hypothesis that the empathy map benefits are similar or equal to the persona method, and (2) determining the efficacy of the empathy map. This experiment was carried out in a project in a partnership with a producer of office supplies and the University of Sao Paulo. The company contacted the university to nominate professionals who could develop a white glue tube improvement project, and it was looking for trainees (novice members with little experience in the user-focused design area). In this way, 25 undergraduate students in the second year of the course Manufacturing and Materials Engineering were indicated, since these students had knowledge about materials (for possible modifications of structure in the glue tube), they needed project experience and they were pursuing a discipline on user-centered design (UCD).

The participants were randomly organized into groups, and they all had guidance from four members of the company (product development coordinator, project management coordinator, member of the R\&D team responsible for usability, research assistant) and from three product development, experts and UCD specialists from the university. For this project, the trainees had to present new concepts for a white glue tube for the company, and during the four months of activity, they followed the same design: first, they would have to understand the users' needs, and then, they would raise product requirements to later generate concepts and test them. To understand user needs, they applied the empathy map method.

The interviews and observations made to apply the method were carried out with 106 children between four and eight years old and six teachers in their respective classrooms (real users). With the result of applying the empathy map, students were able to raise user requirements, transforming them into product requirements and then generating new concepts. The tests were conducted at the company's main site with 40 children and 11 parents (real users). With the users' feedback, the concepts were re-elaborated and presented to the company.

Both the company and the students performed the evaluation of the method. The evaluation performed 
by the company occurred at certain specific phases of the project (called gates) and at the end of the project, when collective interviews were conducted with the four company representatives. The evaluation performed by the students occurred through a questionnaire applied to the students (since it was they who applied the method properly) at the end of the project. This questionnaire was, however, based on the advantages cited in the literature about the method persona (COOPER, 1999; GRUDIN; PRUITT, 2002; HJALMARSSON, 2015), since there are not many advantages cited directly on the empathy map, and both methods have very similar objectives (persona: to understand, describe, and clarify the needs of the user and their behaviors and to focus on the project in terms of these needs (CHANG; LIM; STOLTERMAN, 2008); empathy map: to raise clear hypotheses about users' needs, behaviors, and other attributes (OSTERWALDER; PIGNEUR, 2010). Therefore, it is expected that both methods have similar benefits. The questionnaire followed a 7-point Likert scale (once this is an optimum number of class intervals (SYMONDS, 1924)), where 1 meant "total disagreement," 2 "largely disagreement," 3 "disagreement in parts," 4 "indifferent," 5 "agreement in parts," 6 "largely agreement," and 7 "total agreement". All the students" answers were organized on sheets and then compared. In addition, at the end of the project, a group interview with the four company representatives was carried out to identify advantages observed by the company related to the application of the method.

\section{Results}

In this paper, we sought to evaluate the benefits of the empathy map method, which was applied in a glue tube development project. The results obtained are presented in four sections. First, a description of the case of the application of the empathy map method is presented, and subsequently, the project design phases that the groups followed are detailed (data collection, empathy map elaboration and empathy map analysis).

\subsection{Case description}

The empathy map was applied in partnership with a Brazilian subsidiary of a global company headquartered in Germany. The company produces office supplies (pencils, pens, erasers, glue, etc.). The challenge given to the students was that they were required to propose new concepts for white glue tubes. Members of the company were present throughout the project. The team representing the company included the product development coordinator, the project management coordinator, and the member of the R\&D team responsible for usability.

The main product stakeholders and users interviewed by the students were children, their parents, and their teachers. The project lasted approximately four months. From the observations and interviews carried out by the students, it was possible to identify the profile, needs, complaints, and difficulties of users (children, teachers, and parents). This information was organized in the form of empathy maps. Figure 1 contains examples of these maps, carried out by two groups. From these results, the students elaborated modifications and new concepts for the tube of white glue.

Throughout the project, a constant monitoring of the trainees was established, and, at the end of the project and evaluation of the results, quality testing was carried out, by means of a questionnaire, with the objective of evaluating the benefits of the empathy map method. The trainees presented their concepts for a new white glue tube for the
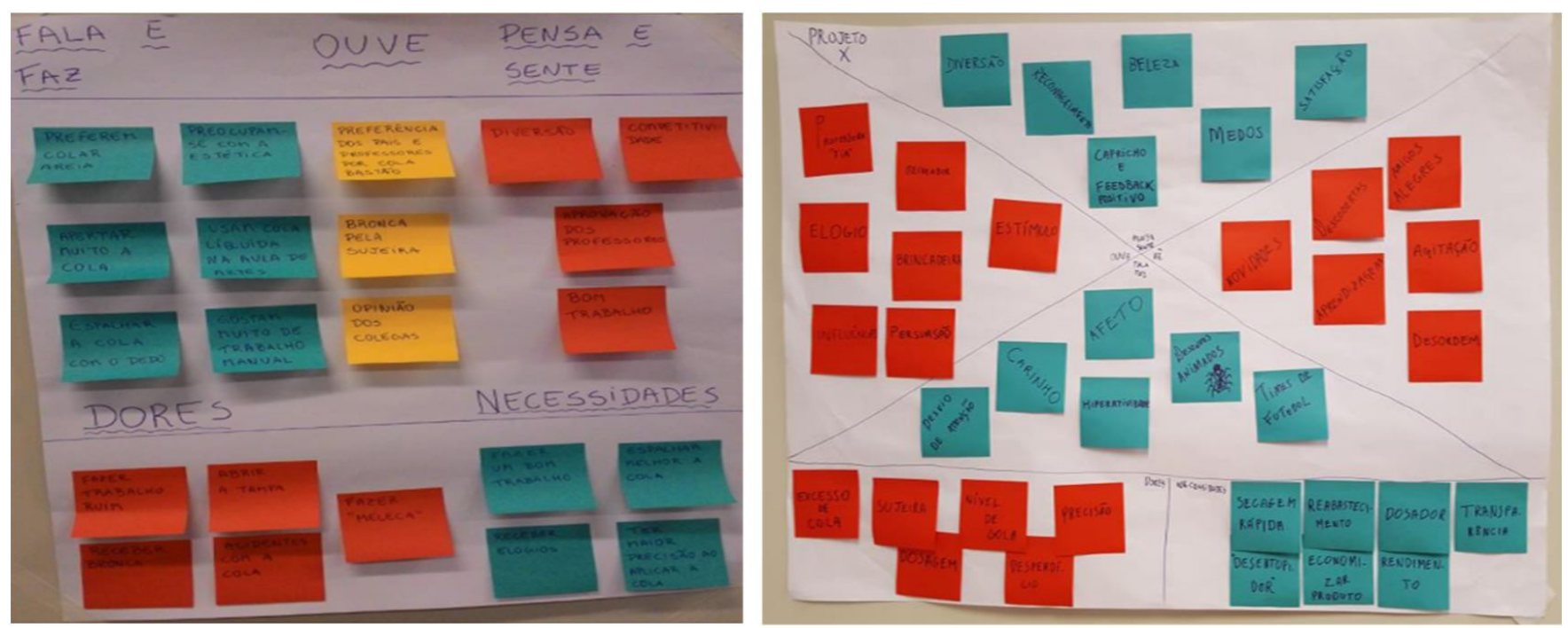

Figure 1. Example of empathy maps of two groups. 
company, which chose the best one. Afterward, the company detailed this concept and launched it in the Brazilian market.

\subsection{Data collection}

For the data collection, the teams defined what would be addressed with the users, what kind of information would be asked or observed and so on. For this, a research protocol was developed (one per team). For the "children" users, the teams proposed dynamics with specific activities to be able to observe the accomplishment of such activities, whereas for the "teachers" users, the teams followed an interview script.

Both the observation protocol and the interview protocol were approved by the company's client research area. The company filed an application for a research permit at the ministry of education and teaching secretariat, and with such authorization in hand and with the approved protocols, it contacted the county board of schools, requesting authorization for the research. There was no need for an ethics committee. All the parents of the students consented to the schools the right of observation and photos. In total, there were 12 hours of observations with 106 children between four and eight years old and 3 hours of interviews with six teachers in their respective classrooms (real users).

\subsection{Empathy map elaboration}

For the organization of the collected information, the empathy map method was used, whose template was offered by the company. The three product development, ergonomics and UCD experts were on hand to answer any queries and help as needed throughout the development of the empathy maps, which lasted four hours per group. The teams used their notes, photos, filming, a sulfite sheet board, sticky notes and pens, and began building the empathy map, until they got a final version, approved by the company and by the experts.

\subsection{Empathy map analysis}

The teams presented to the company the main pains and needs of the users. They were approved and thus it was possible to proceed in the development project of the glue tube concept, generating product requirements. Groups were asked to establish an array of requirements vs. requirements and each group presented some ideas of concepts with those requirements for the company and for the experts.

The representatives of the company selected some concepts and the teams elaborated some prototypes, which were tested with real users provided by the company (40 children and 11 parents). The test lasted about four hours and, from the feedback obtained, the concepts were restructured and presented to the company.

\section{Discussion}

After the empathy map was drawn, the design teams answered a questionnaire in order to evaluate the application of the method. This evaluation was also carried out by the company through interviews at the end of the project. This section presents these results.

\subsection{Design team's perspective}

\subsubsection{Analysis of the method's application}

To evaluate the application of the method, the following two aspects were taken into account: the difficulty to start the application of the method, and the real time of application $v s$. the expected one. These aspects aim to clarify the effectiveness of obtaining good results in the research.

Some studies have pointed out that, although companies understand the importance of creating user empathy, they do not apply methods that take this into account. One hypothesis is that the methods are difficult, time consuming, or even that companies are unaware of such methods. Companies do not want to increase development time because entering the market before their competitor is essential. In this sense, it is important to evaluate whether the application of the method would be a barrier in these respects. The results of the analysis of these aspects are presented in Figure 2. It is worth remembering that the questionnaire applied follows a scale of 1 (total disagreement) to 7 (total agreement).

Four appliers total agreed with the question about real time of application vs. the expected one (Q1); 6 appliers largely agreed and 9 agreed in parts, in other words, 19 appliers (76\%) agreed that the time available to them for understanding and applying the method was sufficient. This means that the time for applying the method is very low, comparing to the whole product development time. In this way, it is totally feasible for companies to apply the empathy map method in the light of the time taken to do so.

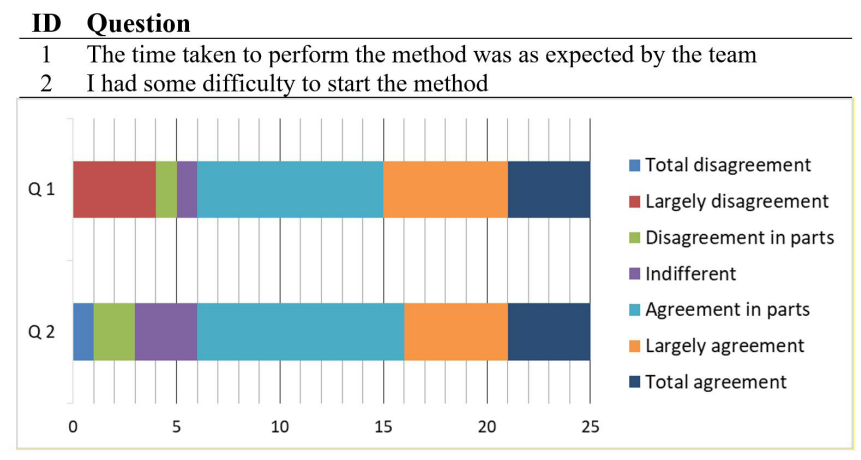

Figure 2. Analysis of aspects related to student motivation in the method's application. 
In the aspect of difficulty to start the application of the method (Q2), the expectations that the students had about the difficulty of applying the method were identified. It is important to evaluate this difficulty since teams tend not to apply methods judged as complex. In addition, methods with high execution difficulty would indicate the need for a team with experience not only in the method but also in UCD. Four appliers are sure that they had difficulties to start the method, and others 15 had some difficulties, that is, for 19 trainees $(76 \%)$, it is difficult to apply the method. It was then asked what were these difficulties, which were:

- Difficulty in using sticky-notes

- Difficulty to start

- Difficulty in understanding what the "hear" and "see" quadrants mean, even with a previous explanation

- Difficulty in organizing information and collate this information in the quadrants of the template.

Observing the difficulties cited by the students, it can be concluded that half of them are not related specifically to the method (use of sticky notes and the beginning of the method). Because the students had never worked on either the method or with sticky notes, it was evident that the lack of experience with the method and with the instrument used may have affected the evaluation.

\subsubsection{Analysis of the method's benefits}

Indications were analyzed regarding how the method contributed in supporting the team with information from users. In the literature, no benefits were identified from the empathy map specifically, so benefits were selected from other user profile methods, which could evaluate the empathy map: make decisions, engage the team, generate concepts, discuss needs, and organize information (Figure 3).

The aspect generation of good concepts solutions (Q3) became a fundamental part of the project since each group had to generate new concepts for the company. Ten appliers total agreed that the perceived insights of applying the method helped in the generation of good concepts for solutions for the white glue tube, and others 14 somehow agreed on that. No one disagreed with the aspect from Q3.

In the aspect organize information (Q4), it was analyzed whether the application of the method helped in the organization of data raised by the students. This organization is extremely important since in the structuring of projects there is a great amount of important information obtained through the users. This aspect obtained 12 responses that totally agreed to this aspect of Q4 and 10 other answers that somehow agreed (total of $88 \%$ of the applicants). Only 3 trainees remained indifferent about this, and no one disagreed with it. This analysis indicates that the organization of the information collected from the users benefited from the application of the empathy map.

In the make decisions aspect (Q5), it was analyzed whether the method assisted in the decision-making and prioritization of requirements for the project. Considering that 13 responses were obtained for "total agreement", 3 for "largely agreement" and 7 for "agreement in parts" (sum of $92 \%$ ), it is noted that, in a general way, the students agreed that the empathy map helped in making decisions. With a more specific analysis due to the high standard deviation, it was noticed that only $8 \%$ of the trainees disagreed with this aspect.

Currently, the aspect of engage the team (Q6) is of great importance and commitment, as it is sought by many working organizations. It was analyzed whether the method contributed to all the students of the group participating in the project, aligning the knowledge raised. Analyzing the 3 answers of total agreement, the 8 of large agreement and the 5 of agreement in parts $(64 \%)$, it can be said that this aspect was also analyzed in a positive way for the trainees. However, there was a high standard deviation in the responses. Only one trainee did not agree that the method helped in team engagement.

In the aspect of discussion about the user's needs (Q7), it was analyzed whether the method facilitated the communication between the members of the group about the user needs, as well as their discussions. Four appliers total agreed with this aspect, 12 largely agreed and 4 agreed in parts (sum of $80 \%$ ), which indicates that students agreed that communication improved with the application of the method. Only five students were indifferent or did not agree with this aspect, and each one was in a different group, which may indicate a certain introversion of the students

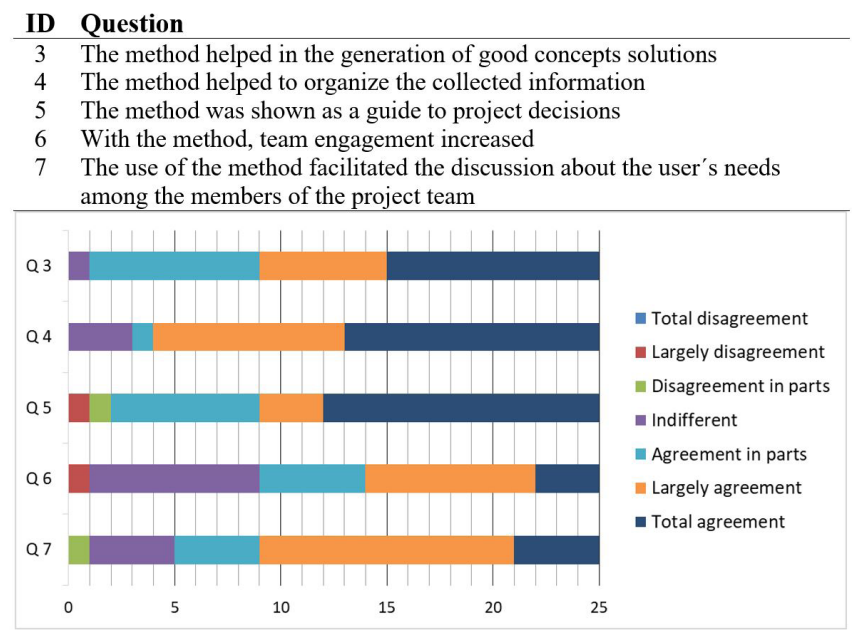

Figure 3. Analysis of the aspects related to the motivation of the students in the method's benefits. 
themselves, influencing their answers. Thus, it is necessary for an entrepreneurial environment to be attentive to the personality of the group's composition, so that everyone feels at ease to express their opinions.

Observing the behavior of each group in all these aspects (Figure 4), it can be noted that some groups had a very positive understanding of the method. For example, Group 2 was a very active group and was clearly very motivated by the project, showing a good interaction with users and with the company. However, Group 3, with the lowest averages for the method, showed personal problems of people management and no empathy for the user of the product, and, at the beginning of the project the students were less motivated. However, the group was able to obtain the minimum requirements for the project. In this way, although the method brings benefits, it is necessary to take into account the personalities of the project team.

\subsubsection{Analysis of the empathy generated by the method}

To understand the empathy generated by the method means to understand the relationships and emotions established between the users and the students, and obtained through the application of the map empathy method. The following aspects were analyzed: generate empathy, understand the user and break prejudices (Figure 5).

In the aspect generate empathy (Q8), it was observed whether the application of the method helped the students to empathize with the user. Analyzing the affirmative answers (5 total agreement, 7 largely agreement and 6 agreement in parts $-72 \%$ in sum), it points out that the trainees agreed that the use of the method helped them to empathize with the users. This aspect, however, had a relatively high standard deviation, due to the $12 \%$ of disagreement and $16 \%$ of indifference. Students who disagreed with this aspect were each one in a different group, which may indicate that the lack of user empathy was a strong personal trait of each student, and not necessarily that the method does not help in the empathy generation.

The objective of the analysis of the aspect understand the user (Q9) was to analyze if the method helped the students in understanding the profile of the users of the product, to understand their daily activities, their hobbies and interests. Eleven appliers total agreed with this aspect, and others 9 and 4 largely agreed and agreed in parts, respectively (sum of 96\%), which indicates that students agreed that the method brought users' comprehension capabilities. Only one student showed indifference regarding this aspect, and no one disagreed.

In the aspect of break prejudices (Q10), it was analyzed whether the method contributed to the students being able to understand the true profile of the user, allowing a break of the anticipated notions and prejudices. The total of 21 appliers (84\%) that agreed somehow with this aspect
(6 total agreed, 8 largely agreed, 7 agreed in parts), indicates that most students agree that the method helped to break the prejudices about users' information. The high standard deviation was due to the $8 \%$ of the students who showed indifference in this response and another $8 \%$ of the students who did not agree that the method brought this benefit.

In Figure 6, the averages of each group on these aspects are shown. By analyzing this figure, it is possible to note the opinion of the students in relation to their respective groups. The aspect of break prejudices is where there is more dispersion of the averages of the groups. Group 1, with the highest average of 6.40 , stands out, indicating that all trainees in this group are largely in agreement that
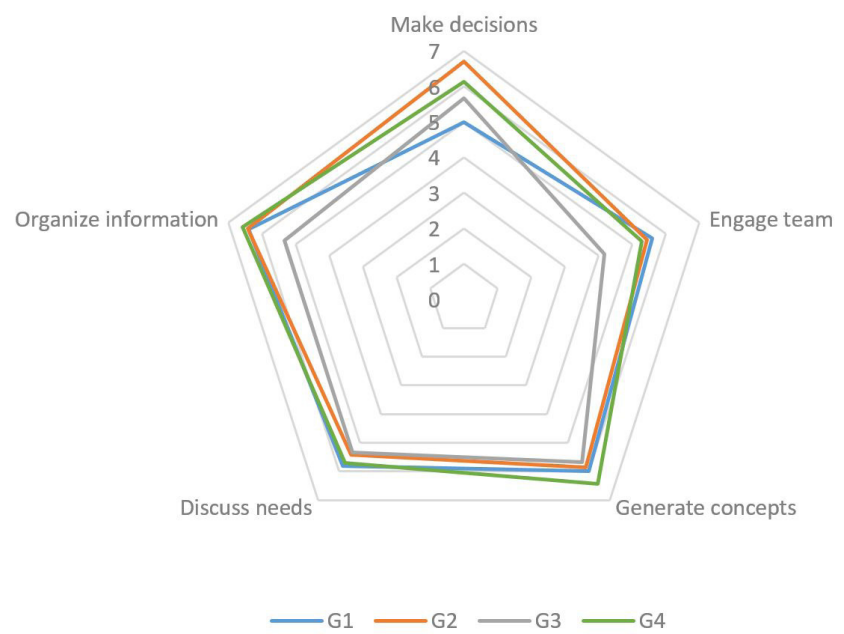

Figure 4. Group averages on aspects of the method benefits.
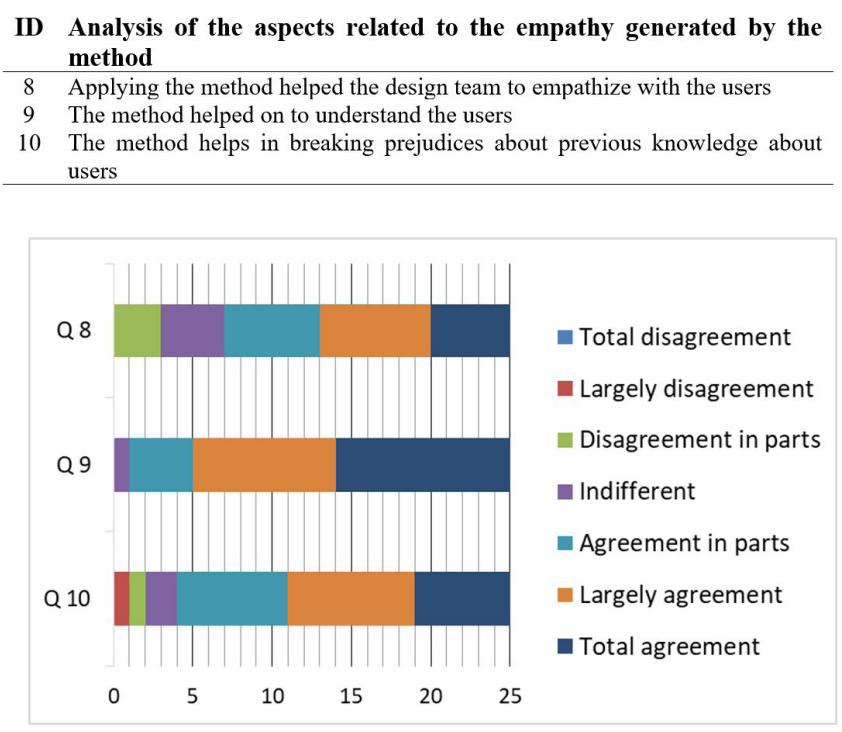

Figure 5. Analysis of the aspects related to the empathy generated by the method. 


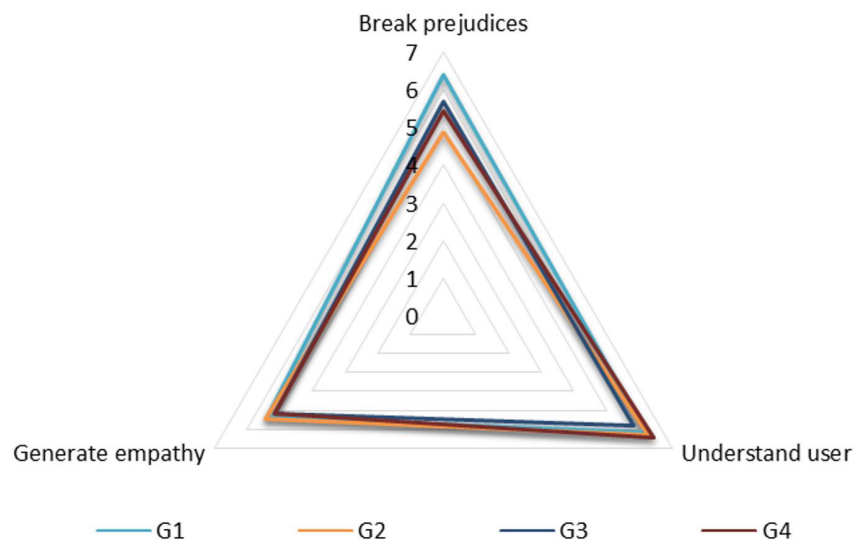

Figure 6. Groups averages on aspects of the method empathy generation.

the method helped to break users' prejudices. This group took advantage of the method with the intention of getting to know the user better and managed to obtain the users' needs in a more relaxed way. Group 2, however, had the lowest average of 4.86 . In this group, $28.6 \%$ of the students disagreed that the method helped to break users' prejudices and $14 \%$ were indifferent. This may be because students in this group might no longer have prejudices about users, which interfered with the outcome of this analysis.

\subsubsection{Analysis of the user needs raised by the method}

According to the company, the groups observed and evaluated in this research obtained a high understanding of the user. It was acknowledged that the students identified what the users really wanted for the white glue tube project. The company praised the work that the students carried out with users from the use of the empathy map method, saying that the method harmoniously defines the user, helping the user's understanding. The following aspects were analyzed: make explicit user needs, get consensus on user needs, and focus on user needs (Figure 7).

In the aspect focus on user needs (Q11), it was evaluated whether the empathy map helped to keep students' focus on the user needs throughout the project (especially during the concept phase). Most of the respondents (88\%) agreed that the method helped them to have a major focus on users' needs. Only one student disagreed with this aspect, and two students were indifferent.

For the aspect get consensus on user needs (Q12), it was analyzed whether it was possible to have a consensus on the users' needs with the application of the method. A total of 21 respondents agreed somehow to this aspect (84\%), 2 respondents showed indifference and 2 disagreed in parts. It is considered then that the majority of the trainees

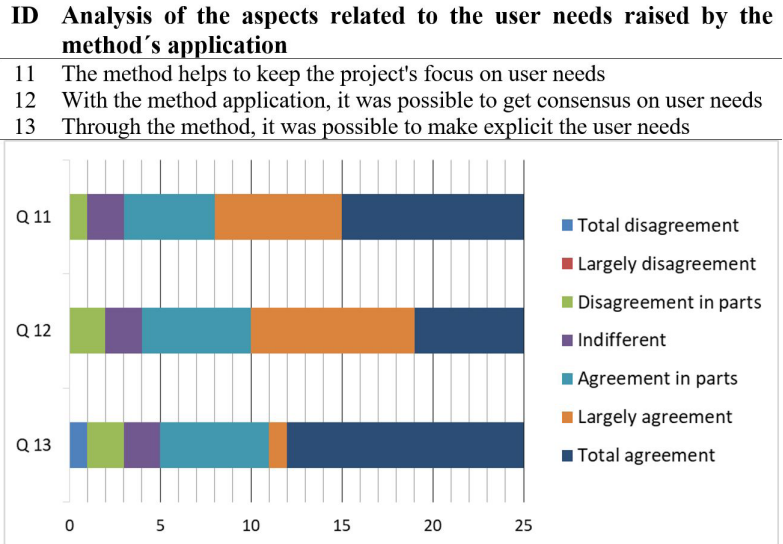

Figure 7. Analysis of the aspects related to the user needs raised by the method's application.

agreed that the use of the method helped to understand, in a consensual way, the needs of the users.

The analysis of the aspect make explicit user needs (Q13) aimed at assessing whether the method made it possible to clarify the users' needs. The application of the method enabled a clear and detailed identification of the users' needs in order to determine possible solutions to the problem of the white glue tube (twenty appliers agreed somehow with this aspect-sum of $80 \%$ ). However, the standard deviation of this aspect was high, due to the $12 \%$ of students who disagreed and $8 \%$ who were indifferent about this aspect. These students, however, were each one in a group, which may indicate that the student had a particular difficulty in raising the needs of the user, influencing the evaluation of this aspect.

In general, the analysis of the needs raised by the method emphasized that the empathy map helped the students to understand, observe, and identify the needs, so that the different groups obtained information and were successful in accomplishing the concepts for a white glue tube.

\subsection{Analysis of the company's satisfaction with the method}

Finally, the satisfaction of the company with the results of the groups, through the application of the empathy map, was analyzed. This satisfaction was analyzed by means of an interview with the company representatives, who followed the results of the groups at two moments during the semester (presentation of concepts and final presentation). The company also received all the material generated by the students, so that the company could fully understand what they accomplished during the semester.

The company's satisfaction was measured by three evidences: the students' understanding of the user's needs, the evaluation of the concepts generated by the students, and the evaluation of the final concept. During the interview 
with the company representatives, they said that all groups identified the users' needs very well, and they could see that the students really understood the users. The company evaluated the concepts generated by the groups, saying that the quality of the results exceeded the expectations of the representatives; none of them was expecting as many details as were presented. It is important to note that the company had never applied the method prior to this contact with the students.

According to the interviewees, it is important to conduct field research with real users and use the information collected to generate concepts, and the empathy map allows this. Based on the final concepts presented by the groups, the company was able to have a good view of the product, what users wanted from it, and what problems users encountered with current white glue tubes. In this way, it was evident that the company also found the method useful.

\section{Conclusions}

This work reports an application of the empathy map method. With this application, it is ossible to conclude that the empathy map's benefits are similar or even equal to those of the persona method. Thus, the analysis of the application of the empathy map indicated that the method brought many benefits to students and the company. The method helped students to observe, understand, and identify user needs, to keep the project's focus on those needs, and to build empathy for the user. The empathy map also helped to organize the information collected with users.

In addition, it can be concluded that its benefits are really the same as those of the persona method and that both the students and the company were satisfied with the results of applying the empathy map. It is believed that the few difficulties encountered by the students in the application of the method can be mitigated with practice.

Despite the satisfactory results, the short time the students had to understand the method before its application was significant for this research. Further application of the method could take a little longer. Another factor that hampered the rapid understanding of the method by the students was the low number of papers with real cases of the use of empathy maps for product development.

For future studies, the empathy map method can be applied and analyzed with teams that already have experience in both UCD and the method. It can also be applied with people of different age groups and in analyzing whether this factor interferes in any way with the results.

\section{Acknowledgements}

This work was supported by Higher Education Personnel Improvement Coordination (Capes).

\section{References}

ABRAS, C.; MALONEY-KRICHMAR, D.; PREECE, J. User-centered design. In: BAINBRIDGE, W. Encyclopedia of human-computer interaction. Thousand Oaks: Sage Publications. p. 445-456, 2004. v. 37. n. 4.

BAGNALL, P.; DEWSBURY, G.; SOMMERVILLE, I. The limits of personas. In: $5^{\text {th }}$ ANNUAL DIRC CONFERENCE, 5., 2005, Edinburgh. Proceedings... Edinburgh, 2005. p. 38-39.

BERTHOLDO, A. P. O. et al. Agile usability patterns for UCD early stages. In: MARCUS, A. (Eds.). Design, user experience, and usability: theories, methods, and tools for designing the user experience. Cham: Springer International Publishing, 2014. p. 33-44.

BRATSBERG, H. M. Empathy maps of the foursight preferences. New York: International Center for Studies in Creativity, 2012.

CHANG, Y.; LIM, Y.; STOLTERMAN, E. Personas: from theory to practices. In: NORDICHI ' $08-5^{\text {th }}$ NORDIC CONFERENCE ON HUMAN-COMPUTER INTERACTION: BUILDING BRIDGES, 5., 2008, Lund, Sweden. Proceedings... New York: ACM Press, 2008. p. 439-442.

CHAPMAN, C. N.; MILHAM, R. P. The personas' new clothes: methodological and practical arguments against a popular method. Proceedings of the Human Factors and Ergonomics Society Annual Meeting, v. 50, n. 5, p. 634-636, 2006.

CHEN, K.; CHOU, W. Emotional experience and interactive design in the workplace. In: MARCUS, A. (Eds.). International conference of design, user experience, and usability. Berlin: Springer, 2013. p. 446-454.

COOPER, A. et al. About face: the essentials of interaction design. 4th ed. John Wiley \& Sons Inc., 2014.

COOPER, A. The inmates are running the asylum. Hoboken: Sams Publishing, 1999.

GRUDIN, J.; PRUITT, J. Personas, participatory design and product development: an infrastructure for engagement. In: PARTICIPATORY DESIGN CONFERENCE, 2., 2002, Sweden. Proceedings... New York: ACM Press, 2002. p. 23-25.

HJALMARSSON, A. Exploring the use of personas in user-centered design of web-based e-services. In: ICONFERENCE, 2015, Newport Beach. Proceedings... California, 2015. p. 1-15.

JURCA, G.; HELLMANN, T. D.; MAURER, F. Integrating agile and user-centered design: a systematic mapping and review of evaluation and validation studies of agileUX. In: AGILE CONFERENCE, 14., 2014, Washington. 
Proceedings... Washington: IEEE Computer Society, 2014. p. 24-32.

KOUPRIE, M.; VISSER, F. S. A framework for empathy in design: Stepping into and out of the user's life. Journal of Engineering Design, v. 20, n. 5, p. 437-448, 2009.

LEONARD, D.; RAYPORT, J. F. Spark innovation through empathic design. Harvard Business Review, v. 75, p. 102-115, jan. 1997.

MAGUIRE, M. Methods to support human-centred design. International Journal of Human-Computer Studies, v. 55, n. 4, p. 587-634, 2001.

MAO, J.; VREDENBURG, K. User-centered design methods in practice: a survey of the state of the Art Paul W Smith. In: CONFERENCE OF THE CENTRE FOR ADVANCED STUDIES ON COLLABORATIVE RESEARCH, 01., 2000, Toronto. Proceedings... Toronto: IBM Press, 2000. p. $12-12$.

MIASKIEWICZ, T.; KOZAR, K. A. Personas and usercentered design: how can personas benefit product design processes? Design Studies, v. 32, n. 5, p. 417-430, 2011.

MÜLLER, M. Management by empathy learning with experience design. In: M/O/T INTERNATIONAL CONFERENCE ON MANAGEMENT LEARNING, 2010, Viena. Proceedings... Klagenfurt: M/O/T School of Management, 2010. p. 1-25.

NORMAN, D. The design of everyday things. New York: Basic Books, 2013.
OSTERWALDER, A.; PIGNEUR, Y. Business model generation. New Jersey: John Wiley \& Sons Inc., 2010.

PLATTNER, H. Bootcamp bootleg. Stanford: Institute of Design, 2010.

PRESSMAN, R. S. Software engineering - A practitioner's approach. 7th ed. New York: McGraw-Hill, 2010.

RIPPON, S. Usability, user-centered design (UCD) and FOSS. In: OPEN SOURCE DEVELOPERS' CONFERENCE, 2006, Melbourne. Proceedings... Melbourne: OSDC, 2006.

SHADISH, W. R.; COOK, T. D.; CAMPBELL, D. T. Experiments and generalized causal inference. In: HOUGHTON, M.(Ed.). Experimental and quasiexperimental designs for generalized causal inference. 2nd ed. New York: Houghton Mifflin Compan, 2002. p. $1-32$.

SILVA, T. S. et al. User-centered design and agile methods: a systematic review. In: AGILE CONFERENCE, 2011, Washington. Proceedings... Washington: IEEE Computer Society, 2011. p. 77-86.

SYMONDS, B. Y. P. M. On the loss of reliability in ratings due to coarseness of the scale. Journal of Experimental Psychology, v. 7, n. 6, p. 456-461, 1924.

VAN KUIJK, J.; VAN DRIEL, L.; VAN EIJK, D. Usability in product development practice; an exploratory case study comparing four markets. Applied Ergonomics, v. 47, 2015.

VIANNA, M. et al. Design thinking: inovação em negócios. Rio de Janeiro: MJV Press, 2012. 